\title{
A practical method of serial bedside measurement of cerebral blood flow and metabolism during neurointensive care
}

\author{
P M Sharples, A G Stuart, A Aynsley-Green, D Heaviside, D A Pay, A McGann, \\ P J Crawford, R Harpin, J A Eyre
}

\begin{abstract}
Acute encephalopathy is a major cause of death and neurological handicap in children. The principle aims of treatment are to provide adequate cerebral blood flow for the brain's metabolic needs and to prevent intracranial pressure rising above the level at which brain herniation occurs. Rational management requires an understanding of the pathophysiological changes in cerebral blood flow and metabolism which occur. The paucity of data on this subject reflects the perceived difficulty of measuring cerebral blood flow and cerebral metabolism in children.

A modification of the Kety Schmidt technique of measuring cerebral blood flow and cerebral metabolism is described. This modification makes it possible to perform serial bedside measurements in children receiving intensive care. This method was used to perform 348 measurements in 58 children. The method was reproducible and no significant complications were encountered. The results indicated that appreciable changes in cerebral blood flow and metabolism could occur in individual patients over time, emphasising the importance of serial measurements. This technique may provide a practical means of monitoring cerebral blood flow and metabolism in very sick children receiving neurointensive care and evaluating the efficacy of treatment.
\end{abstract}

Acute childhood encephalopathy is a condition with a high mortality and morbidity. ${ }^{1}{ }^{2}$ Various forms of treatment may be required according to the aetiology. In all cases, however, the principle aims of treatment are to maintain a cerebral blood flow sufficient to supply the metabolic needs of neurones and glial cells and to prevent intracranial pressure rising to a level liable to result in brain herniation. ${ }^{3}$

The monitoring of intracranial pressure is now an accepted technique in paediatric neurointensive care. ${ }^{45}$ However, there is no currently accepted method of performing serial measurements of cerebral blood flow and cerebral metabolism routinely at the bedside. It is often assumed that cerebral perfusion pressure (mean arterial pressure minus intracranial pressure) provides a useful index of cerebral blood flow, ${ }^{56}$ but cerebral blood flow is dependent upon both cerebral perfusion pressure and cerebrovascular resistance. Variations in cerebrovascular resistance will thus alter the relationship between cerebral perfusion pressure and cerebral blood flow. Moreover, the measurement of cerebral blood flow alone does not provide an index of the adequacy of blood flow for cerebral metabolism. In a normal subject cerebral blood flow will be regulated in accordance with the brain's metabolic requirements but in a child with acute encephalopathy this relationship may be disturbed.

The aim of this paper is to demonstrate that, using the Kety Schmidt technique, ${ }^{7}$ it is possible to perform frequent serial measurements of cerebral blood flow and metabolism in sick infants and children receiving intensive care. Thus it is now potentially possible to prescribe rational treatment and evaluate its efficacy.

\section{Methods}

THEORY

The Kety Schmidt technique, the first quantitative method of measuring cerebral blood flow to be described in man, has been validated against the bubble flow meter. ${ }^{7}$ The method is based on the Fick principle, which states the amount of an inert tracer that is taken up by an organ is equal to the amount delivered by the arterial blood, minus that removed by venous blood in the same time period. Thus:

$$
\left(Q_{B}\right)_{\mathbf{u}}=\left(Q_{A}\right)_{\mathbf{u}}-\left(Q_{v}\right)_{\mathbf{u}} \text { Equation (1) }
$$

Where $\left(Q_{B}\right)_{U}$ is the quantity of substance taken up by the whole brain in time $u,\left(Q_{A}\right)_{u}$ is the quantity of the substance delivered to the brain by the arterial blood in time $u$, and $\left(Q_{v}\right)_{u}$ is the quantity removed by cerebral venous blood in time $u$.

The amount of tracer delivered to the brain or removed from the brain thus equals blood flow multiplied by the arterial or venous concentrations respectively. As the arterial and venous concentrations of such a tracer would vary with respect to time:

$$
\left(Q_{B}\right)_{u}=T F \int_{0}^{u}(A-V) d t \quad \text { Equation (2) }
$$

Where $T F=$ cerebral blood flow $(\mathrm{ml} / \mathrm{min})$, $A=$ arterial tracer concentration $(\mathrm{ml} / \mathrm{l}), \mathrm{V}=$ venous tracer concentration $(\mathrm{ml} / \mathrm{l})$. This can be resolved to:

$$
T F=\frac{\left(Q_{B}\right)_{u}}{\int_{0}^{u}(A-V) d t}
$$

Thus cerebral blood flow (CBF) per gram weight of brain is:

$$
\mathrm{CBF}=\frac{\frac{\left(\mathrm{Q}_{\mathrm{B}}\right)_{\mathrm{u}}}{\mathrm{W}}}{\int_{0}^{\mathrm{u}}(\mathrm{A}-\mathrm{V}) \mathrm{dt}} \quad \text { Equation (4) }
$$

where $W$ represents brain weight in grams $(g)$. 
Kety and Schmidt applied this equation to the measurement of cerebral blood flow in adults using $10 \%$ nitrous oxide, administered by inhalation, as the inert tracer. The denominator was derived from the curves obtained by plotting arterial and cerebral venous nitrous oxide concentrations against time, being equal to the area between the two curves (fig 1). It is not possible to determine the numerator (brain concentration of nitrous oxide) in a living subject, however, if the time $u$ is sufficient for equilibration to have occurred between brain and cerebral venous blood, then the brain tracer concentration will be equal to the partition coefficient of the tracer (the relative amount of tracer dissolved in blood and brain) multiplied by the cerebral venous concentration:

$$
\frac{\left(Q_{B}\right)_{\mathbf{u}}}{W}=S . V_{u} \quad \text { Equation (5) }
$$

Where $S$ represents partition coefficient and $V_{u}$ is the cerebral venous concentration of the tracer at equilibrium. Thus:

$$
\mathrm{CBF}=\frac{\mathrm{S} \cdot \mathrm{V}_{\mathrm{u}}}{\int_{0}^{\mathrm{u}}(\mathrm{A}-\mathrm{V}) \mathrm{dt}} \quad \text { Equation (6) }
$$

Where CBF is cerebral blood flow in $\mathrm{ml}$ per gram of brain per minute $(\mathrm{ml} / \mathrm{g} / \mathrm{min})$.

The blood-brain partition coefficient for nitrous oxide has been shown to be 1.06 in man. ${ }^{8}$ Thus, cerebral blood flow can be obtained if the concentrations of nitrous oxide in arterial and cerebral venous blood can be measured.

The Kety Schmidt method also enables quantitative measurements to be made of cerebral metabolism. If the arterial and cerebral venous concentrations of a cerebral fuel or metabolite

(A)

(B)
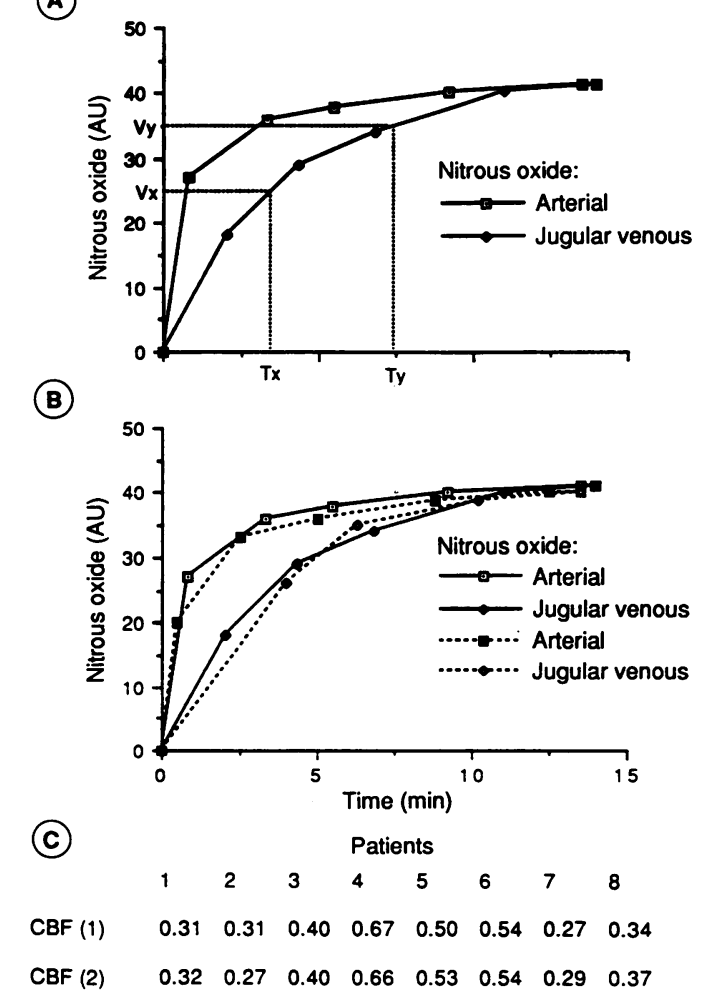

can be measured, the cerebral production or consumption of the substance (cerebral metabolic rate) can be determined:

$$
\mathrm{CMR}=\mathrm{CBF}(\mathrm{A}-\mathrm{V}) \text { Equation (7) }
$$

Where CMR is the cerebral metabolic rate in $\mu \mathrm{mol} / \mathrm{g} / \mathrm{min}, \mathrm{CBF}$ is cerebral blood flow in $\mathrm{ml} / \mathrm{g} / \mathrm{min}, \mathrm{A}$ and $\mathrm{V}$ are the arterial and cerebral venous concentrations of the substance in $(\mu \mathrm{mol} / \mathrm{ml})$.

ADAPTATION OF THE KETY SCHMIDT TECHNIQUE TO PERFORM SERIAL BEDSIDE MEASUREMENTS IN CHILDREN

Sampling of cerebral venous blood

In the original description Kety and Schmidt directly punctured the superior jugular venous bulb to obtain cerebral venous blood uncontaminated by blood of extracranial origin. ${ }^{7}$ Such direct puncture has since been shown to be associated with morbidity. ${ }^{9}$ The Seldinger technique $^{10}$ was used therefore to cannulate the internal jugular vein and a catheter (18 or 20 gauge Ledercath, Vygon) was retrogradely advanced until the tip lay in the superior jugular venous bulb. ${ }^{11} 12$ The position of the cannula tip at the base of the skull was subsequently confirmed by a lateral $x$ ray film of the neck.

The catheter was left in situ and perfused with heparinised normal saline (one unit of heparin per $\mathrm{ml}$, rate $1-3 \mathrm{ml} /$ hour); it was also connected to a pressure transducer and the pressure wave displayed continuously (Simonsen and Weel Monitor, System 8000, Triscope) principally to allow early recognition of catheter blockage.

\section{Administration of tracer}

A modified three block rotameter (air/oxygen/ nitrous oxide) enabled $10 \%$ nitrous oxide to be administered via the ventilator circuit to the patient while maintaining a constant inspired oxygen concentration. During the period of nitrous oxide administration six paired, timed, blood samples $(0.2 \mathrm{ml})$ were sequentially withdrawn from a peripheral arterial catheter and the catheter sited in the superior jugular venous bulb (fig 1). The blood was collected into preheparinised $1 \mathrm{ml}$ plastic disposable syringes which were immediately capped. Each blood sample was then injected through a gas tight butyl rubber septum (Pierce and Warriner) into

Figure 1(A) Arterial and jugular venous nitrous oxide saturation curves obtained by plotting the concentration of nitrous oxide in six paired, timed, blood samples withdrawn during the period of $10 \%$ nitrous oxide administration against time. $V_{x}$ and $V_{y}$ represent successive measured nitrous oxide concentrations at times $T_{x}$ and $T_{y}$. The nitrous oxide concentration is plotted in arbitrary units $(A U)$ as only the difference in concentration over time between the arterial and venous nitrous oxide saturation curves is required. $(B)$

Duplicate arterial and jugular venous nitrous oxide saturation curves, obtained by taking 12 paired, timed, blood samples from the aterial and superior jugular catheters during the period of administration of $10 \%$ nitrous oxide. The solid lines represent the curves used to calculate one value for cerebral blood flow, $C B F(1)$, and the dotted lines represent the curves used to calculate the second value, $C B F(2) .(C)$ Cerebral blood flow in $\mathrm{ml} / \mathrm{g} / \mathrm{min}$ obtained from performing duplicate measurements, $C B F(1)$ and $C B F(2)$, in eight patients (see methods). 
$3.5 \mathrm{ml}$ glass vial (Pierce and Warriner) using a 25 gauge hypodermic needle. A second 25 gauge needle was inserted through the septum at the time of injection to avoid an increase in pressure within the bottle. Both needles were then withdrawn and the blood samples maintained at room temperature until the nitrous oxide concentration was measured.

Measurement of the concentration of nitrous oxide To ensure that the nitrous oxide in the gaseous phase was in equilibrium with that in the blood sample a vortex was created in each sample by a 10 second agitation of the vial (Rotamixer, $\mathrm{BDH}) .^{1314}$ The gas above the blood sample was then sampled and its concentration assayed using infrared spectroscopy (ADC, M 715). ${ }^{15} 16$

The coefficient of variation of the microassay technique was measured by performing six determinations of nitrous oxide concentration on $0.2 \mathrm{ml}$ samples of heparinised blood tonometered at $37^{\circ} \mathrm{C}$ with three mixtures of nitrous oxide $(5 \%, 10 \%$, and $15 \%)$ and oxygen. The coefficient of variation of the technique ranged from $1 \cdot 4 \%$ to $3 \cdot 4 \%$.

\section{Calculation of cerebral blood flow}

The arterial and cerebral venous nitrous oxide saturation curves were plotted from the concentrations of nitrous oxide in the six paired, timed, blood samples (fig 1). The areas under each curve were calculated using a computer programme and the equation:

$$
\text { Area }_{c}=\sum \frac{\left(T_{x}-T_{y}\right)\left(V_{x}+V_{y}\right)}{2} \quad \text { Equation (8) }
$$

Where Area $_{c}$ is the area under the curve and $V_{x}$ and $V_{y}$ represent successive measured nitrous oxide concentrations at times $T_{x}$ and $T_{y}$.

The numerator in the Kety Schmidt equation (6) was obtained by multiplying the blood brain partition coefficient for nitrous oxide $(1 \cdot 06)^{8}$ by the cerebral venous oxide concentration at equilibrium (fig 1).

The denominator in equation (6) was derived by subtracting the area under the venous curve from the area under the arterial curve. Cerebral blood flow in $\mathrm{ml} / \mathrm{g} / \mathrm{min}$ was thus calculated.

Reproducibility of cerebral blood flow measurement In eight subjects the reproducibility of the measurement of cerebral blood flow was determined by taking 12 timed, paired, blood samples from the arterial and superior jugular catheters during the period of administration of nitrous oxide (fig 1). This enabled two separate values for cerebral blood flow to be calculated for each subject. ${ }^{17}$ Each measured value of cerebral blood flow was assumed to be the 'true' value plus error where the errors were assumed to have a normal distribution with variance sigma squared. The estimate of error was then calculated as:

$$
\sigma^{2}=\sum \frac{\left(\mathrm{x}_{1}-\mathrm{x}_{2}\right)^{2}}{2 \mathrm{n}} \quad \text { Equation (9) }
$$

\section{Cerebral metabolism}

At the end of the period of nitrous oxide administration, a blood sample $(0.5 \mathrm{ml})$ was withdrawn from both the arterial catheter and the superior jugular venous bulb for analysis of blood gases and oxygen content. Blood gas analysis ( $\mathrm{pH}$, arterial carbon dioxide tension $\left(\mathrm{PaCO}_{2}\right)$, arterial oxygen tension $\left(\mathrm{PaO}_{2}\right)$, and base excess) was performed using a Radiometer blood gas analyser (Corning 1312). The arterial oxygen saturation $\left(\mathrm{SaO}_{2}\right)$ and haemoglobin concentration $(\mathrm{Hb})$ were measured at the bedside by a Co-Oximeter (Corning 2500) and arterial oxygen content calculated according to the formula ${ }^{18}$ :

$$
\begin{aligned}
& \text { Oxygen content }=\mathrm{Hb} \times \mathrm{SaO}_{2} \times 1 \cdot 39+ \\
& \left(0.023 \times \mathrm{PaO}_{2}\right)
\end{aligned}
$$

\section{Results}

\section{JUGULAR VENOUS CANNULATION}

Cannulation of the superior jugular venous bulb was attempted in 78 children and was successful in 72 (age range 2 weeks-16 years, median 2 years, weight $2 \cdot 4-58 \mathrm{~kg}$, median $13 \cdot 3 \mathrm{~kg}$ ). In six children cannulation was not successful (age range 6 weeks -6 years, median 4 months, weight range $2.4 \mathrm{~kg}-20 \mathrm{~kg}$, median $5.37 \mathrm{~kg}$ ); two were under $3 \mathrm{~kg}$ and another child was later found to have anomalous venous anatomy. In 68 cases the procedure was entirely uncomplicated. Puncture of the carotid artery occurred in four children but bleeding was easily controlled with local pressure.

The jugular venous bulb cannulae remained in situ for a median of 2 days, range 1-8 days. There were no clinical problems related to the cannulae. Of 47 catheter tips submitted for microbiological cultures, 40 showed no evidence of bacterial contamination and seven showed a scanty growth of skin commensal organisms.

\section{Duration of nitrous oxide administration}

To be able to calculate cerebral blood flow it is important to ensure that the duration of administration of nitrous oxide is sufficient to achieve equilibration of the nitrous oxide between blood and brain (fig 1). The period required is dependent upon the rate of blood flow to the brain. Kety and Schmidt administered 10\% nitrous oxide by inhalation for 10 minutes. ${ }^{7}$ In normal adult subjects this was found to be sufficient to ensure blood-brain equilibration, ${ }^{7}$ indicated by the concentration of nitrous oxide in the cerebral venous blood becoming equal to the concentration in arterial blood (fig lA).

Figure 2 graphs the time to achieve blood brain equilibration for nitrous oxide versus the calculated cerebral blood flow for 331 measurements made in the present study. In only $87 / 331$ (26\%) measurements was equilibration achieved by 10 minutes. In $276 / 331(83 \%)$ of the measurements however equilibration was achieved after 15 minutes of nitrous oxide administration. More than 15 minutes was required to reach equilibration when blood flows were very low, with 42 of these 55 cerebral blood flows being less than $0 \cdot 30 \mathrm{ml} / \mathrm{g} / \mathrm{min}$. 


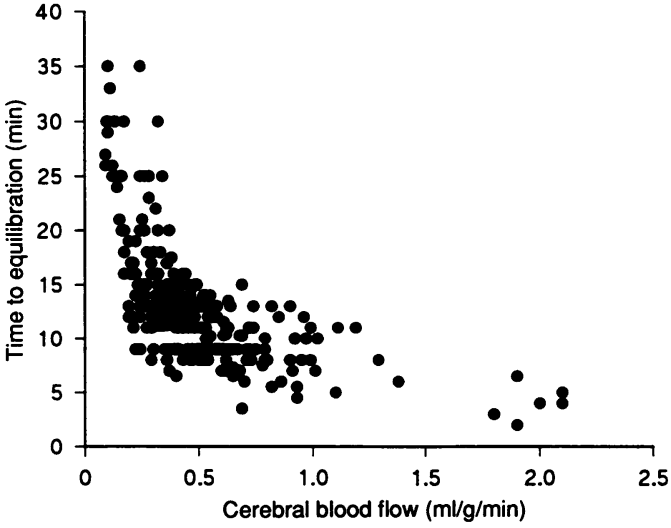

Figure 2 Time to blood-brain equilibration of nitrous oxide in relation to cerebral blood flow. Blood-brain nitrous oxide equilibration is defined as having been reached when the cerebral venous concentration of nitrous oxide is within $5 \%$ of the arterial concentration.

Reproducibility of measurements of cerebral blood flow

Figure 1B shows two arterial and venous saturation curves for nitrous oxide obtained from the same subject after the taking of duplicate, paired, blood samples during a period of administration of nitrous oxide (see methods). Figure $1 \mathrm{C}$ tabulates the paired values for cerebral blood flow obtained. There is close agreement between the two values for all eight subjects. The estimate of error ( $\sigma$ see equation (9) in methods) was $1.58 \%$ with a $95 \%$ confidence interval of $1 \cdot 02 \%$ to $2 \cdot 88 \%$. Thus the measured values are likely to lie within $\pm 3 \%$ of the putative 'true' value.

MEASUREMENTS OF CEREBRAL BLOOD FLOW AND METABOLISM

Three hundred and forty eight measurements of cerebral blood flow and metabolism were performed in 58 children. The median age was 2 years (age range 2 weeks-16 years) and the median weight $12.6 \mathrm{~kg}$ (range $2.4-58.0 \mathrm{~kg}$ ). The median number of measurements performed in each child was 6 (range 1-23). It was possible to repeat measurements as frequently as every half hour if desired.

There was wide intersubject and intrasubject variability in cerebral blood flow results which ranged from $0 \cdot 09-2 \cdot 13 \mathrm{ml} / \mathrm{g} / \mathrm{min}$. Figure $3 A$ shows the median value of cerebral blood flow plus the range for each of the 58 subjects in relation to their age. There was no systematic variation in values of cerebral blood flow with age.

There was similarly wide intersubject and intrasubject variability in the results for the cerebral metabolic rate for oxygen with a range of $0.03-5.79 \mu \mathrm{mol} / \mathrm{g} / \mathrm{min}$. Figure 3B graphs the median value of the cerebral metabolic rate and the range for each of the subjects in relation to their age.

In a normal subject, in whom cerebral blood flow and metabolism are closely coupled, the arterio-jugular venous oxygen difference remains constant. In a patient with acute encephalopathy this relationship between cerebral blood flow
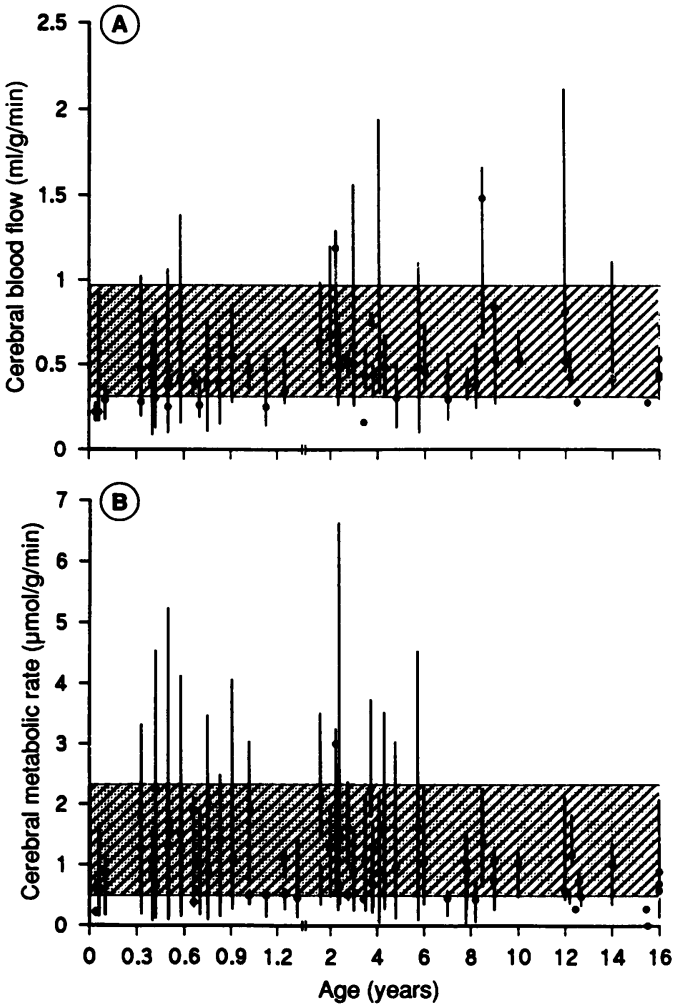

Figure 3 Cerebral blood flow $(A)$ and cerebral metabolic rate for oxygen $(B)$ for all 58 subjects in relation to age. The points represent the median values for each child, and the vertical lines indicate the range. The hatched area represents the limits of the range of cerebral blood flow $(A)$ and cerebral metabolic rate $(B)$ reported by Settergen et al in normal children. ${ }^{20}$

and metabolism may be lost and abnormally high or low cerebral oxygen extraction may be found. ${ }^{19}$ An arterio-jugular venous oxygen concentration difference which is greater than normal indicates a cerebral blood flow that is low relative to cerebral metabolic rate while, conversely, an arterio-jugular venous oxygen difference that is lower than normal implies that cerebral blood flow is relatively excessive for the brain's metabolic demands. ${ }^{19}$

Figure 4 shows the relationship between cerebral blood flow and the arterio-jugular venous oxygen difference for all 348 measurements. The limits of the normal ranges for these parameters ${ }^{20}$ are also shown. Using this model each result can be categorised into five broad groups (A, B, C, D, and E). In group $A$ the cerebral blood flows and arterio-jugular venous oxygen concentration differences are normal, suggesting that there is a normal relationship between cerebral blood flow and metabolism. In groups $B$ and $C$ there is absolute or relative hypoperfusion; group B demonstrates increased cerebral oxygen extraction associated with low cerebral blood flow indicating hypoperfusion; group $\mathrm{C}$ demonstrates a high arterio-jugular venous oxygen extraction associated with normal or increased cerebral blood flow indicating a cerebral blood flow relatively insufficient for a high cerebral rate. In group $D$ cerebral blood flow is within or above the normal range and oxygen extraction is decreased, indicating a cerebral blood flow that is excessive for meta- 


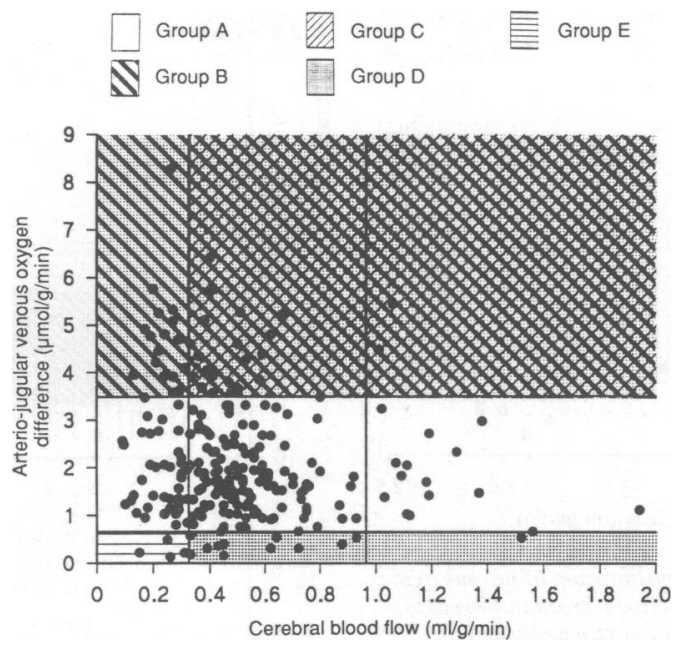

Figure 4 The relationship between cerebral blood flow and the arterio-jugular venous oxygen difference for all 348 measurements. The vertical lines represent the limits of the range of cerebral blood flow results reported in normal children by Settergen et al ${ }^{20}$ and the horizontal lines represent the limits of the range of arterio-jugular oxygen

differences. ${ }^{20}$ The plain and variously hatched areas

represent the five groups $(A, B, C, D, E)$ into which an individual set of results can be classified.

bolic requirements. Finally, in group $\mathrm{E}$, both cerebral blood flow and arterio-jugular venous oxygen differences results are below the normal range, indicating very low cerebral blood flow associated with low cerebral blood flow.

\section{Discussion}

This study has shown that the Kety Schmidt technique can be used in very sick children to perform serial, quantitative measurements of cerebral blood flow and metabolism on the intensive care unit. The Kety Schmidt technique has been used previously to measure cerebral blood flow and metabolism in very small numbers of children with acute encephalopathy, ${ }^{21-24}$ but no other group has described the use of this technique to perform serial measurements in large numbers of very sick children.

The results of our study demonstrate that significant changes in cerebral blood flow and cerebral metabolic rate may occur over time within an individual subject (fig 3). Such wide variation during the course of the illness emphasises the need for a technique that allows repeated measurements of cerebral blood flow and metabolism to be performed; serial measurements also permit an assessment of the efficacy of therapeutic manoeuvres.

Other currently available methods of measurement cannot be used either at the bedside or to perform serial measurements. Thus, techniques that employ radioisotopes have limitations because of the hazards of repeated exposure to irradiation. ${ }^{25}$ Positon emission tomography (PET) and single photon emission tomography (SPECT) have the additional disadvantage that the patient has to be transported to the scanner. ${ }^{25} 26$ Infrared spectroscopy may have potential as a method of performing continuous, focal measurements of cerebral blood flow and metabolism in comatose children ${ }^{27}$; however this technique is still being developed (J S Wyatt, personal communication).

The suitability of the Kety Schmidt technique for use in children has hitherto been a source of controversy. A major review of methods for measuring cerebral flow dismissed the technique as associated with major technical problems. ${ }^{28}$ These difficulties have arisen from two sources: first, sampling blood from the superior bulb of the internal jugular vein and second, performing reproducible measurements of nitrous oxide concentration in small volumes of blood.

The original technique of direct puncture for sampling superior jugular bulb blood was technically difficult and associated with morbidity. ${ }^{9}$ However, percutaneous retrograde cannulation using the Seldinger ${ }^{10}$ technique is an easier procedure $^{11}$ and allows an indwelling catheter to remain in situ for the duration of intensive care. We have experienced no significant complications from this procedure and similar findings have recently been reported by Gale $e t a l^{12}$ and Goetting and Preston. 29

The original method for the measurement of the nitrous oxide concentration in blood, the Van Slyke manometric technique, required large volumes of blood and considerable expertise. ${ }^{15} 2330$ Gas chromatographic analysis enables the volume of blood to be greatly reduced, but is technically demanding and labour intensive. ${ }^{31}$ The need for laboratory based equipment precludes immediate bedside measurement of cerebral blood flow. The use of infrared spectroscopy, however, overcomes these problems and enables the concentration of nitrous oxide to be measured rapidly and easily at the bedside in only $0.2 \mathrm{ml}$ of blood.

Although other tracers, including krypton $85^{17}$ and tritiated water, ${ }^{32}$ have been used in the Kety Schmidt technique, low concentration nitrous oxide still has significant advantages, being safe, inexpensive, readily available, and stable. Moreover, the partition coefficient of nitrous oxide has been shown not to be altered by differing concentrations of lipid and water ${ }^{33} 34$ and thus is unlikely to change with age or if a subject develops cerebral oedema.

The duration of administration of nitrous oxide to ensure blood-brain equilibration has also been a source of controversy. ${ }^{35}{ }^{36}$ It is clear both theoretically and from our results, that the period required is dependent upon the cerebral blood flow. ${ }^{35} 36$ In the light of our data (fig 2) we now administer nitrous oxide for 15 minutes. If the cerebral venous concentration of nitrous oxide is found not to be equal to the arterial concentration at the end of the measurement period, the venous curve is extrapolated ${ }^{35} 36$ to within $5 \%$ of the arterial value using a best fit monoexponential curve defined by least squares and a longer period of administration is used for subsequent measurements.

A major advantage of the Kety Schmidt technique is that normal ranges for cerebral blood flow and metabolic rate in children have been published by Kennedy and Sokoloff ${ }^{37}$ and Settergen et al. ${ }^{20} 31$ However, although the arterio-jugular venous oxygen concentration differences reported by both groups are the 
same (mean $2 \cdot 17 \mu \mathrm{mol} / \mathrm{ml}$ ) there are significant differences in cerebral blood flow (mean 1.06 and $0.65 \mathrm{ml} / \mathrm{g} / \mathrm{min}$ respectively) and cerebral metabolic rates (mean 2.30 and $1.35 \mu \mathrm{mol} / \mathrm{g} / \mathrm{min}$ respectively) between the two groups. The values reported by Settergen et al are similar to the results for cerebral blood flow and cerebral metabolic rate in normal adult subjects quoted by other authors obtained using the Kety Schmidt technique 738 and xenon 133 . $^{19}$ Moreover, the nine children reported by Kennedy and Sokoloff were unsedated and restrained while femoral arterial and direct superior jugular venous bulb punctures were performed. ${ }^{37}$ Thirty five other children were entered into the study but became so uncooperative that measurements could not be completed. The results were thus obtained from highly stressed children which may explain the high cerebral metabolic rates and consequent high cerebral blood flows. Settergren et al studied 70 children during general anaesthesia before elective surgery. ${ }^{20}$ Anaesthesia was maintained with $50 \%$ nitrous oxide. A recent review has concluded that the effects of nitrous oxide anaesthesia on cerebral blood flow and metabolism in man are likely to be minimal. ${ }^{40} \mathrm{We}$ therefore concluded that results reported by Settergren et $a l^{20}$ were more likely to represent cerebral blood flow and cerebral metabolism in normal unstressed children than those of Kennedy and Sokoloff ${ }^{37}$ and these were used as our normal reference range.

Figure 4 illustrates how results for cerebral blood flow and arterio-jugular oxygen difference, available at the bedside, might be interpreted and aid clinical management. Thus, a child whose results fall within both normal ranges (group A) may not require treatment to alter cerebral blood flow or metabolism, unless intracranial pressure is significantly raised. If reduction of intracranial pressure is attempted by reducing cerebral blood flow then cerebral metabolic rate may need to be reduced in parallel. In contrast, a child with a cerebral blood flow which is relatively low for cerebral metabolic demands (groups B and C) is at risk of sustaining cerebral ischaemic injury and further lowering of cerebral blood flow would be inappropriate. Treatment might indeed aim to increase cerebral blood flow or lower cerebral metabolic rate. A child with relative hyperaemia (group D) would require no treatment unless intracranial pressure was raised, in which case reduction of cerebral blood flow might be appropriate.

At present the Kety Schmidt method is a research technique that will increase understanding of the pathophysiology of acute childhood encephalopathy. However, our success is using this method to perform frequent, serial measurements in relatively large numbers of children receiving intensive care, and the straightforward way in which the results can be interpreted, suggest that the technique may have potential in the future for the clinical monitoring of individual children and the evaluation of therapeutic interventions.

We would like to acknowledge financial support from the
Scientific and Research Committee of the Northern Regional Health Authority, Action Research for the Crippled Child, the Sir Jules Thorn Charitable Trust, the Wellcome Trust, and the Mason Medical Foundation, advice from Dr John Matthews and Dr Kim Bartlett, and the cooperation of the consultants at Newcastle General Hospital and the Freeman Hospital who cared for the children. JAE is a Wellcome Senior Research Fellow in Clinical Science.

1 Sharples PM, Storey A, Aynsley-Green A, Eyre JA. Avoidable factors contributing to death of children with head injury. BMF 1990;300:87-91.

2 Seisha SS, Seisha MMK, Sacdera RK. Coma in childhood. Dev Med Child Neurol 1977;19:614-28.

3 Miller JD. Head injury and brain ischaemia-implications for therapy. Br $\mathcal{F}$ Anaesth 1985;57:120-9.

4 Minns RA. Intracranial pressure monitoring. Arch Dis Child 1984;59:486-8.

5 Newton RW. Intracranial pressure and its monitoring in childhood: a review. F Roy Soc Med 1987;80:566-70.

6 Tasker RC, Matthew DJ, Helms P, Dinwiddie R, Boyd S. Monitoring in non-traumatic coma. Part I: invasive intracranial measurements. Arch Dis Child 1988;63:888-94.

7 Kety SS, Schmidt CF. The nitrous oxide method for the quantitative determination of cerebral blood flow in man: theory, procedure and normal values. $\mathcal{f}$ Clin Invest 1948; 27:476-83.

8 Kety SS, Harmel MH, Brommell HT, Rhode CB. The solubility of nitrous oxide in blood and brain. $\mathrm{f}$ Biol Chem 1948;173:487-96.

9 Gibbs EL, Lennox WG, Gibbs FA. Bilateral internal jugular blood. Comparison of A-V differences, oxygen-dextrose ratios and respiratory quotients. Am $\mathcal{F}$ Psychiatry 1945;102: $184-90$.

10 Seldinger S. Catheter replacement of the needle in percutaneous arteriography. Acta Radiol 1953;39:368-76.

11 Swedlow DB, Kettrick RG, Raphaely RC. Jugular bulb catheterisation in children. Crit Care Med 1981;9:287.

12 Gale MO, Frewen TC, Armstrong RF, et al. Jugular venous bulb catheterisation in infants and children. Crit Care Med 1989;17:385-8.

13 Molloy MJ, Latto IP, Rosen M. Analysis of nitrous oxide concentrations in whole blood. An evaluation of an equilibration technique. Br $\mathcal{F}$ Anaesth 1973;45:556-61.

14 Saloojee Y, Cole P. Estimation of nitrous oxide in blood. Gas chromatographic analysis of trace or analgesic levels.
Anaesthesia 1978;33:779-83. Anaesthesia 1978,33:779-83.

Lawther PJ, Bates DV. A method for the determination of nitrous oxide in blood. Clin Sci 1952;12:91-5.

16 Sonander $\mathrm{H}$, Stenquist $\mathrm{O}$, Nilsson $\mathrm{K}$, Úrinary $\mathrm{N}_{2} \mathrm{O}$ as a measure of biologic exposure to nitrous oxide

17 Lassen NA, Munck $O$. The cerebral blood flow in man determined by the use of radioactive krypton. Acta Physiol Scand 1954;33:30-49.

18 Benumof JL. Respiratory physiology and respiratory function during anesthesia. In: Miller RD, ed. Anesthesia volume 2. 2nd Ed. New York: Churchill Livingstone, 1986:1115-63.

19 Obrist WD, Langfitt TW, Jaggi JLL, Cruz J, Gennarelli T. Cerebral blood flow and metabolism in comatose patients with acute head injury. $\mathcal{f}$ Neurosurg 1984;61:241-53.

20 Settergen G, Linblad BS, Persson B. Cerebral blood flow and exchange of oxygen, glucose, ketone bodies, lactate, pyruvate and amino acids in anaesthetised children. Acta Paediatr Scand 1980;69:457-65.

21 Frewen TC, Sumabat WO, Del Maestro R. Cerebral blood flow, metabolic rate, and cross-brain oxygen consumption in brain injury. $f$ Pediatr 1985;107:510-3.

22 Frewen TC, Kisson N. Cerebral blood flow and brain oxygen extraction in Reye syndrome. F Pediatr 1987;110:903-5. 3 Swedlow DB, Lewis LE. Measurement of cerebral blood flow in children. Anesthesiology 1980;53:S160.

24 Swedlow D, Frewen T, Watcha W, Bruce DA. Cerebral blood flow, AJDO2 and $\mathrm{CMRO} 2$ in comatose children. In: Go KG, Baethmann A. eds. Brain edema. New York: Plenum Press, 1984:365-72.

25 Kirkham FJ. Intracranial pressure and cerebral blood flow in non traumatic coma in childhood. In: Minns RA, ed. Problems of intracranial pressure in childhood. Clinics in developmental medicine 113/114. New York: Mac Keith Press with Blackwell Scientific Publications, 1991 (in press).

26 Frackowiak RSJ. PET scanning: can it help resolve management issues in cerebral ischaemic disease? Stroke 1986;17: 803-7.

27 Wyatt JS, Edwards AD, Azzopardi D, Reynolds EOR. Magnetic resonance and near infrared spectroscopy for investigation of perinatal hypoxic-ischaemic brain injury. Arch Dis Child 1989;64:953-63.

28 Kirsch JR, Traystman RJ, Rogers MC. Cerebral blood flow measurement techniques in infants and children. Pediatrics 1985;75:887-95.

29 Goetting MG, Preston G. Jugular bulb cathererization: experience with 123 patients. Crit Care Med 1990;18: 1220-3.

30 Baird HW, Garfunkle JM. A method for the measurement of cerebral blood flow in infants and children. $f$ Pediatr 1953;42:570-5.

31 Settergen G, Linblad BS, Persson B. Cerebral blood flow and exchange of oxygen, glucose and ketone bodies, lactate, pyruvate and amino acids in infants. Acta Paediatr Scand
$1976 ; 65: 343-53$. 
32 Warrell DA, Veall N, Chantavanich P, et al. Cerebral anaerobic glycolysis and reduced cerebral oxygen transport in human cerebral malaria. Lancet 1988;ii:534-8.

33 Mapleson WW, Evans DE, Flook V. The variability of partition coefficients for nitrous oxide and cyclopropane in the rabbit. $B r \mathcal{F}$ Anaesth 1970;42:1033-41.

34 Kozam RL, Landau SM, Cubina JM, Lukas DS. Solubility of nitrous oxide in biologic fluid and myocardium. $\mathcal{J} A p p l$ of nitrous oxide in biol
Physiol 1970;29:593-7.

35 Lassen NA, Klee A. Cerebral blood flow determined by saturation and desaturation with krypton: an evaluation of the inert gas method of Kety and Schmidt. Circ Res 1965;26:26-32. 36 Siesio BK. Brain energy metabolism. Chichester: John Wiley
and Sons, 1978:63-6.
37 Kennedy C, Sokoloff $\mathrm{L}$. An adaptation of the nitrous oxide method to the study of the cerebral circulation in children; normal values for cerebral blood flow and cerebral metabolic rate in childhood. F Clin Invest 1957;36:1130.

38 Scheinberg P, Stead EA. The cerebral blood flow in male subjects as measured by the nitrous oxide technique Normal values for blood flow, oxygen utilisation and peripheral resistance, with observations on the effect of tilting and anxiety. $\mathcal{F}$ Clin Invest 1949;28:1163-71.

39 Cohen PJ, Alexander SC, Smith TC, Reivich M, Wollman H. Effects of hypoxia and normocarbia on cerebral blood flow and metabolism in conscious man. 7 Appl Physiol 1967;23: 183-9.

40 Michenfelder JD. Nitrous oxide. In: Michenfelder JD, ed. Anesthesia and the brain. New York: Churchill Livingstone, 1988:51-65.

Levamisole for steroid dependent nephrotic syndrome

They're always there, aren't they? I often see them as ward visitors so that they don't spend their lives waiting in outpatients. There's usually one, or two, at the end of each ward round. They need their height and blood pressure checking and steroid dosage adjusting. Some get cyclophosphamide but not with any great enthusiasm on my part (inwardly at least). Some have even been known to opt for 'alternative' therapies, receiving whatever is deemed good for 'kidney disease'. I don't mind that; it's when the alternative therapist starts to interfere with the steroid dose that I begin to lose my cool just a little. They, of course, have steroid responsive, frequently relapsing nephrotic syndrome.

There is evidence of deficient $T$ cell function in this condition and therefore some rationale for using an immunostimulant drug such as levamisole, although the mode of action of this drug is unknown. A multicentre, randomised, placebo controlled, double blind trial done under the auspices of the British Association for Paediatric Nephrology has recently been reported (Lancet 1991; 337: 1555-7). Sixty one children completed the trial. All had steroid responsive, frequently relapsing nephrotic syndrome and had relapsed on maintenance treatment with prednisolone at a dose of at least $0.5 \mathrm{mg} / \mathrm{kg}$ body weight on alternate days. Remission was induced with prednisolone before starting levamisole $(2.5 \mathrm{mg} / \mathrm{kg}$ to a maximum of $150 \mathrm{mg}$ on alternate days) or placebo. The prednisolone was tailed off over eight weeks but the levamisole or placebo continued for 16 weeks.

At the end of 16 weeks $13 \%$ of the placebo group and $45 \%$ of those given levamisole had not relapsed $(p=0.008)$. Most (10 of 14) of the levamisole treated patients in remission at the end of the trial, however, relapsed within the next three months. No serious toxicity was recorded.

It seems that levamisole offers some advantage as long as it is being taken. How long can we afford to give it for? Could we avoid steroid toxicity by alternating periods on steroid and on levamisole? Far more questions than answers come to mind. Judicious use in selected cases seems justified. It's certainly not a miracle cure. 